\title{
EMPRESAS DO SETOR DE ENGENHARIA CIVIL DIANTE DO CENÁRIO PANDÊMICO DO COVID-19: UM ESTUDO DE CASO NA EMPRESA LINEAR ENGENHARIA EIRELI
}

\section{ARTIGO ORIGINAL}

OLIVEIRA, Emanuel Bruno da Silva1, BRASIL, Leilane dos Santos ${ }^{2}$, NEVES, Luwendell Henrique Maciel $^{3}$, ALMEIDA, Victor da Silva ${ }^{4}$, ROBERTO, José Carlos Alves $^{5}$

OLIVEIRA, Emanuel Bruno da Silva. Et al. Empresas do setor de engenharia civil diante do cenário pandêmico do Covid-19: Um estudo de caso na empresa Linear Engenharia Eireli. Revista Científica Multidisciplinar Núcleo do Conhecimento. Ano. 06, Ed. 11, Vol. 13, pp. 87-112. Novembro de 2021. ISSN: 2448-0959, Link de acesso:

https://www.nucleodoconhecimento.com.br/administracao/setor-de-engenharia, DOI: 10.32749/nucleodoconhecimento.com.br/administracao/setor-de-engenharia

\section{RESUMO}

Este artigo visa apresentar um estudo de caso aplicado à empresa de pequeno porte denominada Linear Engenharia Eireli, atuante no ramo da Engenharia Civil. O objetivo geral constituiu-se em estudar os impactos causados pela pandemia no desempenho dos aspectos organizacionais da empresa, buscando a melhoria na área funcional de menor desenvolvimento e elaboração. O presente artigo surgiu a partir da análise do desempenho das áreas funcionais, onde foi identificado o setor de Marketing como o mais problemático. A questão norteadora pretende responder:

\footnotetext{
${ }^{1}$ Graduando do curso de Administração.

${ }^{2}$ Graduando do curso de Administração.

${ }^{3}$ Graduando do curso de Administração.

${ }^{4}$ Coorientador. Mestre em Engenharia de Processos. Pós-Graduando em Neuropsicopedagogia Institucional. Especialista em Gestão Estratégica de RH. Graduado em Administração e Pedagogia.

${ }^{5}$ Orientador. Mestre em Engenharia de produção. Especialista Logística empresarial. Graduado em Administração com Ênfase em Marketing.
}

RC: 102091

Disponível em: https://www.nucleodoconhecimento.com.br/administracao/setor-deengenharia 
como pode ser reinventado o negócio para suprimir as dificuldades e diferenciar-se no mercado da Construção Civil, diante a outras empresas do mesmo ramo, considerando os impactos da pandemia do Covid-19? Teve-se como objetivo a identificação das ações e dos aspectos responsáveis para a execução do planejamento, que foi realizada por meio de sete perguntas orientadoras. A metodologia empregada para a realização deste estudo de caso foi o planejamento de ações interventivas e a ferramenta $5 \mathrm{~W} 2 \mathrm{H}$. Espera-se que com a introdução das ações interventivas sejam geradas diversas vantagens que resultem no crescimento da organização e no aumento do elo de relacionamento entre empresa e público.

Palavras-chave: Engenharia Civil, Construção Civil, Covid-19, Planejamento Estratégico.

\section{INTRODUÇÃO}

Este artigo apresenta um estudo de caso aplicado à empresa de pequeno porte denominada Linear Engenharia Eireli, atuante no ramo da Engenharia Civil. O objetivo geral constituiu-se em compreender os impactos causados pela pandemia do Covid-19 no desempenho dos aspectos organizacionais da empresa e desenvolver, por meio de um planejamento estratégico específico, soluções para o aperfeiçoamento e mobilidade na área funcional que apresenta o grau de operação mais crítico.

O estudo foi auxiliado por objetivos específicos que consistem em: identificar a área de menor grau de desempenho, buscar métodos estratégicos de aplicabilidade a partir de um planejamento de ações específicas, utilizar ferramentas propícias para 0 alcance dos resultados esperados, e proporcionar ações para a adaptação do negócio ao novo normal em função da pandemia.

O estudo de caso foi desenvolvido com base no diagnóstico organizacional realizado na empresa em questão, visando à análise das áreas funcionais, onde foi identificada a área de Marketing como sendo a mais crítica e menos desenvolvida da 
empresa. Após discutir a situação atual em que se encontra a organização, indagase, portanto, sobre como reinventar o negócio, suprimindo as dificuldades proporcionadas pela pandemia do novo Coronavírus, e diferenciar-se frente às outras empresas do ramo da Engenharia Civil.

A metodologia empregada foi o planejamento de ações interventivas e a ferramenta orientadora utilizada deu-se pela $5 \mathrm{~W} 2 \mathrm{H}$, sendo que ela objetiva a identificação das ações e os aspectos responsáveis para a execução do planejamento. Espera-se que, com a introdução das ações interventivas, sejam geradas diversas vantagens para o crescimento da organização e o aumento do elo de relacionamento entre empresa e público. Acredita-se que as dificuldades possam ser suprimidas e que a melhora na área funcional mais crítica propiciará o crescimento da organização como um todo.

O artigo está dividido em seis seções: a primeira é a presente introdução; a segunda seção aborda a fundamentação teórica da concepção deste estudo, discutindo sobre a contextualização relacionada ao mercado da Construção Civil e ramos; a terceira fase expõe os procedimentos metodológicos utilizados nesta pesquisa, as técnicas de coleta de dados, a análise e os métodos usados para o desenvolvimento deste artigo; a quarta parte é a análise de dados, discutindo e apresentando os resultados; e na quinta e sexta seção, são apresentadas as considerações finais e referências bibliográficas, respectivamente.

\section{EMPRESAS DO SETOR DA CONSTRUÇÃO CIVIL E PANDEMIA DO COVID-19}

Na maior parte dos países industrializados, o setor da Construção Civil é um dos mais significativos na contribuição para o produto interno bruto (PIB) e, além disso, também gera um impacto significativo na saúde e segurança dos trabalhadores, tornando-se uma das indústrias, economicamente e socialmente, mais fundamentais (YOON et al., 2013). 
A construção civil não se baseia apenas em construtoras e incorporadoras, ela é muito mais ampla. Inicia-se a partir do desenvolvimento de estudos sobre as viabilidades de um empreendimento. O setor supracitado abrange diversas atividades de produtividade de obras, do planejamento e projeto à administração da sistematização de transportes, barragens, operação das estações de tratamento de água, entre outros (MEC, 2002).

\subsection{A INDÚSTRIA DA CONSTRUÇÃO CIVIL ANTES DA PANDEMIA}

Para entender a atuação das empresas de Engenharia Civil frente ao cenário pandêmico do Covid-19, é necessário compreender o contexto e o momento em que a indústria da Construção Civil se encontrava antes do acontecimento do primeiro caso do novo Coronavírus no Brasil.

O PIB (Produto Interno Bruto) divulgado pelo IBGE (Instituto Brasileiro de Geografia e Estatística), em março de 2020, finalizou 2019 com crescimento de 1,1\%, totalizando $R \quad \$ 7,257$ trilhões de reais. Isso refere-se ao terceiro resultado positivo, após as altas de 2017 e 2018, que interromperam as quedas de 2015 e 2016. A indústria da Construção Civil obteve 1,6\% em construção, o melhor comportamento após 5 anos em queda no desempenho (CBIC, 2020).

Segundo Martins (2020), houve uma frustração do desempenho, que ocorreu justamente no interesse da habitação de interesse social, onde há $90 \%$ de déficit habitacional do território brasileiro. Porém, apesar de demonstrar o crescimento, ainda sim, ele considera que o segmento poderia ter obtido alta superior, devido à falta de contratações por muitos períodos, sobretudo em 2019 e início de 2020.

Oliveira (2019), ressalta que apesar de uma melhoria no desempenho, a crise econômica que assolava e que ainda assola o país afetou o setor da Construção Civil em peso. O autor explica que esse segmento é considerado como um termômetro de muita importância para a economia e que reflete rapidamente os 
impactos causados tanto pelo crescimento econômico quanto pela estagnação ou recessão.

\subsection{A ATUAÇÃO DAS EMPRESAS DO RAMO DA ENGENHARIA CIVIL FRENTE AO CENÁRIO PANDÊMICO DO COVID-19}

A indústria da construção civil foi uma das mais atingidas pela pandemia. As relutâncias mais visíveis foram as paralisações de obras, a redução das jornadas de trabalho, bloqueios na exportação e alta do dólar. A pandemia trouxe diversas mudanças mundialmente, transformando a forma de comunicação e a vivência em sociedade, principalmente nas empresas de Engenharia e Projetos, onde se mostrou necessário se reinventar e se adequar ao novo normal (ARMAC, 2021).

\subsubsection{ISOLAMENTO SOCIAL E A PARALISAÇÃO}

Segundo Silva (2020), o impacto mais perceptível no setor da construção civil foi o isolamento social. $O$ autor explica que para proteger a população e enfrentar a crise desencadeada pela pandemia do Covid-19 no Brasil, governos estaduais e municipais providenciaram, de forma imediata, a paralisação de diversos serviços e atividades comerciais não essenciais no mês de março de 2020, inclusive as relacionadas à construção, sendo que apenas o funcionamento de estabelecimentos essenciais poderia continuar efetuando suas demandas, como farmácias, padarias e os supermercados.

Desse modo, toda a cadeia de suprimentos da Construção Civil foi atingida, proporcionando a dificuldade de as empresas manterem suas equipes trabalhando em obras e escritórios. Porém, mesmo com as adversidades da pandemia, esse cenário trouxe um panorama diferente e, positivamente, propiciou a avaliação e a reflexão do segmento para efetuar a otimização de seus processos (ARMAC, 2021). 


\subsubsection{DESEMPENHO DOS ASPECTOS ORGANIZACIONAIS}

\subsubsection{ADMINISTRAÇÃO}

Sobral e Peci (2013), definem a administração como um processo de coordenação do trabalho dos integrantes da empresa e da destinação dos recursos organizacionais que visa atingir os objetivos definidos de modo eficiente.

Para Chiavenato (2014), a administração exerce um papel essencial na solução dos mais graves problemas que impactam atualmente o mundo moderno, uma vez que o exercício básico da Administração é conseguir realizar os processos por meio do capital humano e dos recursos disponíveis de forma eficaz.

Segundo Coltre (2014), o teórico Henri Fayol foi o primeiro a utilizar as funções básicas do administrador, sendo elas: planejar, organizar, controlar e coordenar. Em seguida, essas funções foram readequadas por Peter Drucker, onde definiu-se as funções do administrador como PODC: planejar, organizar, dirigir e controlar.

Conforme Santos (2020), a rotina de um administrador de uma empresa é baseada em vários momentos de decisões e planejamentos, sendo que esses direcionam as organizações para o caminho ideal. Com essa pandemia, fica clara a obrigatoriedade de os administradores reverem alguns conceitos ultrapassados, considerando o fato de que o cenário contribui para as mudanças repentinas do modo de gestão das empresas.

Diante disso, Santos (2020) ainda afirma que o principal desafio do administrador é analisar e pôr em uma balança os erros e acertos, com o objetivo de identificar as ameaças e as oportunidades que os impactos do Covid-19 trouxeram até o presente momento, pois entende-se que diversas organizações se adaptam e atualmente se aproveitam das tecnologias, ferramentas e novos nichos que surgiram, para se diferenciar. Outras, infelizmente, findam na paralisação de suas atividades frente aos prejuízos e não buscam reinventar-se. 


\subsubsection{PRODUÇÕES E OPERAÇÕES}

A administração da produção é caracterizada como uma atividade que visa gerenciar estrategicamente recursos desprovidos de atividades (humanas, tecnológicas, referenciais e outros), de sua interação e dos processos de produção, sendo que entregam bens e serviços objetivando $O$ atendimento das necessidades e/ou desejos de qualidade, tempo e custo dos clientes (CORRÊA; CORRÊA, 2011, p. 24).

Já as operações, segundo Freitas (2016), são exercícios desenvolvidos pela organização em diversos setores que, ao final, proporcionam o bom funcionamento, segundo a visão de negócios. Desse modo, o autor considera que as operações são funções vitalícias de uma empresa.

Por conseguinte, Lunardelli (2021) diz que as organizações mais afetadas pela pandemia no quesito operação e produção, foram as construtoras e incorporadoras, nas quais não há processos digitalizados e a maior parte dos trabalhos é realizada de forma manual, por exemplo, o controle por meio de Excel e documentação física. A autora ressalta que a produção no canteiro de obras também foi prejudicada devido à falta de atuação do escritório, engenheiros e gestores de obras presencialmente, impossibilitando a condução do serviço, propiciando obras paralisadas por tempo indeterminado.

Segundo Mott (2021), os escritórios de engenharia e arquitetura conseguiram, com mais efetividade, inserir-se à nova realidade, com diversos modelos de produção e operação. Um dos novos modelos de trabalho mais utilizados por essas empresas é, no geral, o Home Office ou modelo híbrido. Ele explica que o Home Office se torna uma tratativa da nova realidade para diversos negócios, mas que demanda altos investimentos para ser totalmente eficiente e produtivo. E sobre o modelo híbrido, este é considerado o mais ideal para alcançar o equilíbrio entre a vida pessoal e profissional, consistindo em trabalhar um ou dois dias por semana no escritório e o restante em casa. 
Para Coelho (2021), o modelo de Home Office não será desintegrado no póspandemia, já que a aplicação desse modelo tem como finalidade proporcionar flexibilidade e economia, permitindo que o funcionário produza tanto no escritório quanto em casa.

\subsubsection{RECURSOS HUMANOS}

Mesmo desenvolvendo meios para conter a proliferação do vírus, o comportamento e os hábitos da sociedade foram totalmente alterados. Isso engloba as mudanças e as adaptações na gestão de pessoas nas empresas. Dados indicaram um aumento substancial na criação de empregos na construção civil. Na verdade, pode ser considerado como um dos setores que mais empregam, mesmo na ocorrência de uma pandemia (CAGED, 2020).

Sendo assim, Mott (2020) afirma que, para continuar com a produtividade, evitando a estagnação trabalhista em meio a pandemia, utiliza-se o Home Office como uma possibilidade realista para as organizações. Além de alternativo, tornou-se tendência e foi regulamentado com a Reforma Trabalhista de 2017.

Mesquita (2020) frisa que esse modelo de trabalho fez com que muitas empresas continuassem ativas e, sobretudo, respeitando as medidas de segurança decretadas pela a OMS. Asseguraram, com isso, a empregabilidade de muitos colaboradores e a rotatividade do capital humano e financeiro nas empresas.

Segundo Azevedo (2021), uma pesquisa do Global Wellness Institute estipulou que $65 \%$ das empresas estariam investindo em saúde mental e bem-estar dos funcionários durante a pandemia, para que a estimativa de desempenho de produção não sofresse queda constante. Algumas organizações do segmento da construção civil estão indo além e criando novas ações para a valorização do capital humano, o que tem resultado em colaboradores mais motivados e produtivos.

Com estes aspectos positivos, é essencial frisar a importância da construção civil no processo de retomada econômica do Brasil, principalmente em um momento de 
crise causada pela pandemia do Covid-19. Handa (2021), reforça a importância extrema da Construção Civil para a economia, pois o setor é responsável por um dos maiores geradores de emprego e renda do país.

\subsubsection{FINANÇAS}

Foi difícil manter as obras, sem a mão de obra e os insumos necessários. Inicialmente, tudo foi mais dificultoso, por ser uma situação desconhecida e por não haver um preparo prévio para o impacto financeiro, ainda mais com as medidas protetivas impostas (TCP SISTEMAS, 2021).

Nesse contexto, é perceptível a baixa nos investimentos e nas demandas no setor da construção civil. Contudo, Dau (2020) afirma que a pandemia impulsionou as empresas a inovarem obrigatoriamente, encontrando meios solúveis de retomada de vendas, obras e a realização de serviços, sempre enfatizando a utilização das medidas protetivas contra o vírus.

A economia brasileira cresceu $1,2 \%$ no primeiro trimestre de 2021, comparando-se ao último trimestre de 2020. O setor da construção civil cresceu 2,1\% no mesmo período. Isto posto, para que a indústria da construção civil seja favorecida até o fim da pandemia, é necessário que haja um conjunto de pontos fundamentais, como o oferecimento de linhas de créditos acessíveis, lançamentos residenciais, reformas, a utilização da digitalização dos processos e contratações remotas (CBIC, 2021).

\subsubsection{MARKETING}

Uma maneira de se reinventar e driblar as adversidades impostas pela pandemia do Covid-19, por exemplo, é investir no Marketing e transformá-lo em uma das ferramentas primordiais para o aumento de clientes, para fechar novos negócios na prestação de serviços, dentre outros objetivos. Obter a habilidade de conduzir clientes para diversos panoramas em relação a empresa, encaminhando-os para 
visualizarem os pontos benéficos, os valores, a qualidade e a relevância, torna-se uma questão de sobrevivência (AGÊNCIA 404, 2020).

Kotler (2012) diz que o marketing é de suma importância. Ele explica que subestimar a utilização dessa ferramenta e optar por deixá-la de lado acabou por se tornar o motivo de muitas empresas falharem. $O$ administrador deve reconhecer o papel fundamental que o marketing tem na construção da identidade de marcas fortes e no bom relacionamento com clientes, contribuindo para a valorização da empresa.

Para a empresa que deseja se diferenciar em um mercado tão competitivo e impactado pelas mudanças ocorridas pela pandemia, é primordial que haja foco na elaboração de planos técnicos, para a obtenção de metas e estratégias. Kotler (2012, p. 77) afirma que "as metas indicam aquilo que a unidade de negócios deseja alcançar; a estratégia é um plano de ação para chegar lá".

Conforme Aranha (2021), o tipo de marketing que disparou devido ao isolamento social, foi o Marketing Digital. Foram desenvolvidas e melhoradas uma série de técnicas, de modo que a implementação delas resultou-se em ótimos desempenhos para os aspectos organizacionais das empresas.

A utilização dos canais digitais encontra-se como solução das dores de potenciais clientes, pois, esses canais, tais como redes sociais, blogs, sites e outras ferramentas, fomentam a interatividade com o público (PEÇANHA, 2020).

Segundo Kotler (2017), o papel mais importante exercido pelo marketing digital é a promoção da ação e defesa da marca. O marketing digital é mais compacto e de fácil controle em relação ao marketing tradicional, preocupando-se em proporcionar resultados diretos, enquanto o foco do marketing tradicional está em iniciar a interação com os clientes, o que não é sugerido no cenário de pandemia em que a sociedade se encontra.

Diante desse cenário, observa-se que as empresas que focam no marketing digital e assumem o desenvolvimento do planejamento estratégico sob esses canais 
conseguem ganhar maior visibilidade e reconhecimento da marca, resultando em um bom relacionamento com os clientes e no aumento das vendas, envolvendo a empresa de diferentes maneiras e conectando-as com os canais de atendimento oferecidos por essas redes.

\section{MATERIAIS E MÉTODOS}

\subsection{PROCEDIMENTOS METODOLÓGICOS}

Para atingir o objetivo de compreensão e análise da atuação de empresas da área de engenharia e arquitetura frente ao cenário pandêmico do coronavírus, é necessário entender os procedimentos metodológicos utilizados para a elaboração deste artigo.

Segundo Lakatos e Marconi (1990), não existe ciência sem a utilização de métodos científicos. A pesquisa baseia-se em um conjunto de atividades sistemáticas e racionais, denominadas métodos, com os quais se desenvolve com maior economia e segurança o estudo, permitindo o alcance do objetivo e desenvolvendo caminhos a serem seguidos.

Desta forma, nesta seção, a premissa para o desenvolvimento deste artigo iniciou-se a partir da aplicação da linha de raciocínio do método indutivo. Barros e Lehfeld (2014) explicam que o método da indução é um processo mental que parte de dados suficientemente particulares, com os quais se deduz uma autenticidade de aspecto amplo ou universal não abrangente nas partes analisadas.

\subsubsection{QUANTO À NATUREZA}

Quanto à natureza de pesquisa, no que se diz respeito ao propósito e à contribuição científica que o artigo trará, faz-se uso da pesquisa básica, com o propósito de gerar conhecimento de novos fatos em relação à atuação das empresas da área de engenharia neste cenário pandêmico do Covid-19; e configura-se como uma pesquisa aplicada, com intuito de proporcionar soluções para déficits encontrados.

RC: 102091

Disponível em: https://www.nucleodoconhecimento.com.br/administracao/setor-deengenharia 
A Pesquisa Básica ou Pura, é, para Barros e Lehfeld (2014), mais uma hipótese de raciocínio que diz respeito a fatos existentes. Sua característica não consiste em uma intervenção, de forma imediata, nem ocasiona modificações da realidade social. O principal objetivo é voltado para o amparo de uma necessidade intelectual de compreender os fenômenos deliberados.

Cervo; Bervian e Silva (2007) seguem a mesma concepção, isto é, defendem que o tipo de pesquisa induz o pesquisador à busca pela satisfação de uma necessidade intelectual por meio do conhecimento.

Já a pesquisa aplicada engloba-se ao redor das adversidades existentes no exercício das instituições, organizações, grupos ou atores sociais. Está atrelada ao desenvolvimento de diagnósticos, identificação de problemas e propostas de soluções. Respondem a uma demanda formulada por "clientes, atores sociais ou instituições" (Thiollent, 2009).

\subsubsection{QUANTO AOS MEIOS}

Quanto aos meios, utilizou-se da aplicabilidade da pesquisa de campo e da pesquisa bibliográfica. Conforme Fachin (2012), a pesquisa bibliográfica é o pilar para as demais. Lakatos e Marconi (2009) explicam que a realização da pesquisa bibliográfica se dá a partir de materiais disponíveis, complementada com as pesquisas realizadas anteriormente, a partir de documentos impressos.

Já a pesquisa de campo é empregada com a finalidade de reunir informações e/ou conhecimentos a respeito de um determinado problema para o qual se investiga uma resposta, ou de uma hipótese que se queira evidenciar, ou, ainda, serve para encontrar novos fenômenos ou as relações entre eles. Constitui-se como uma maneira de observar fatos e fenômenos e a forma como ocorrem naturalmente a partir da coleta de dados a eles relativos; há, também, o registro de variáveis que se pressupõem relevantes para a análise (LAKATOS; MARCONI, 2011). 


\subsubsection{QUANTO AOS FINS}

Quanto aos fins de pesquisa, prevaleceu o tipo de pesquisa descritivo. Perovano (2014) esclarece que o processo descritivo visa à identificação, registro e análise das características, fatores ou variáveis que fazem relação com o fenômeno ou processo. Pode ser compreendida também como estudo de caso, no qual, após a coleta de dados, é efetuada uma investigação dos casos considerando as variáveis para um consecutivo desígnio dos efeitos resultantes em uma organização, sistema de produção ou produto.

\subsection{CARACTERÍSTICAS DA EMPRESA}

A empresa utilizada para 0 desenvolvimento da análise sobre a atuação de empresas do ramo da Engenharia Civil frente ao cenário pandêmico do Covid-19 é a Linear Engenharia Manaus Eireli, empresa de pequeno porte, localizada na Rua Waldemir Cordeiro, Alvorada II, na cidade de Manaus, Amazonas.

A organização atua no setor de engenharia e projetos e mostra-se conhecida entre empreiteiros, construtoras particulares, instituições públicas, buscadores por fiscalização, projetos arquitetônicos e consultorias.

\section{RESULTADOS E DISCUSSÕES}

Apresenta-se, nesta seção, a partir dos resultados obtidos nos estudos desenvolvidos na etapa do Diagnóstico Organizacional, considerando a atuação da empresa do segmento da construção civil frente a situação em que a população mundial se encontra, os dados analisados e avaliados concernentes aos aspectos essenciais do desempenho das áreas funcionais existentes, identificando os déficits de desempenho e áreas de atuação com melhor laboração. 
Tabela 01 - Coeficientes de Desempenho

\begin{tabular}{|l|l|}
\hline Áreas Funcionais & Coeficiente \\
\hline Marketing & 0,6 \\
\hline Produção e operações & 4,2 \\
\hline Finanças & 4,7 \\
\hline Recursos humanos & 2,7 \\
\hline Administração & 3,4 \\
\hline & \\
\hline
\end{tabular}

Fonte: Elaborado pelos autores com base na coleta de dados, em 2021.

Gráfico 01 - Medição de desempenho

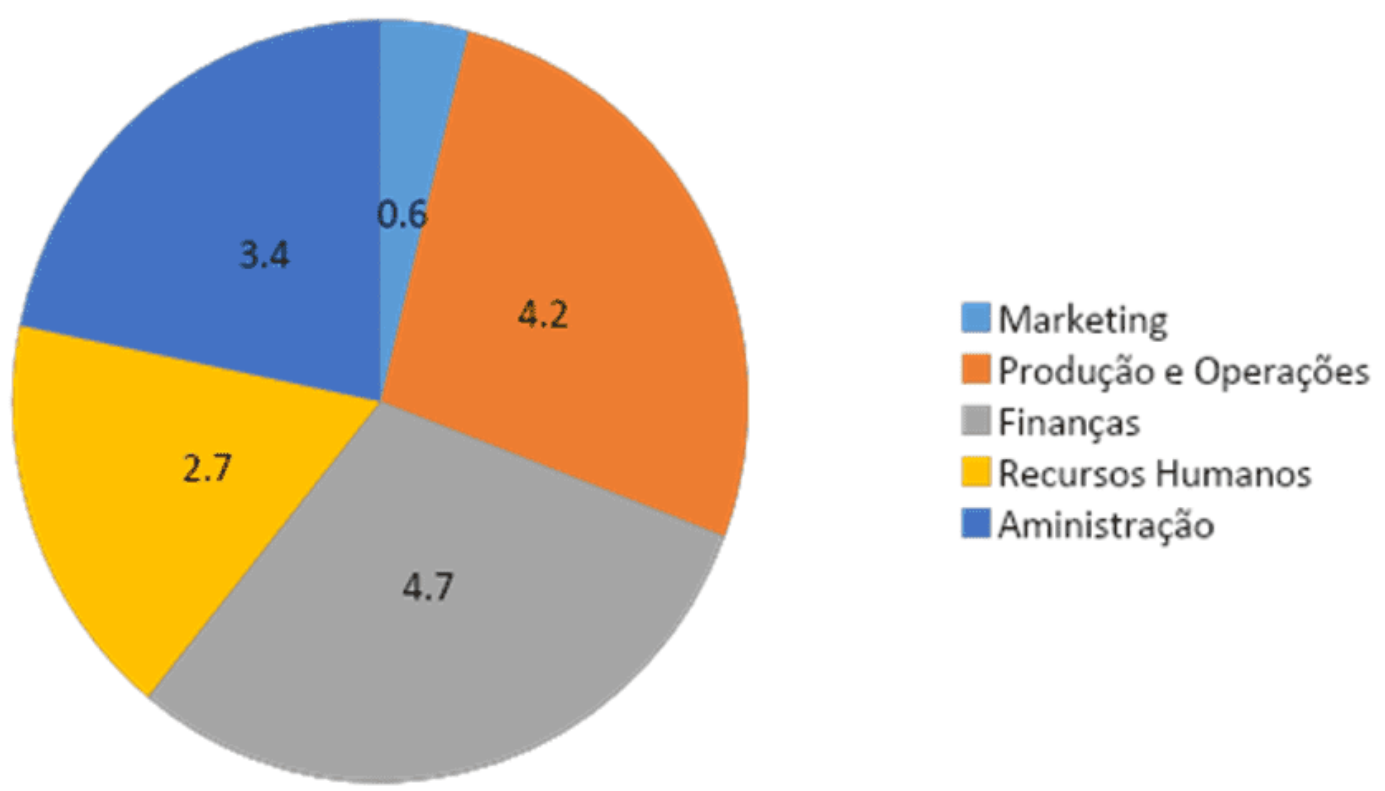

Fonte: Elaborado pelos autores com base na coleta de dados, em 2021.

Pode-se observar na tabela 01 e no gráfico 01 que a área de finanças, mesmo em frente ao cenário pandêmico do Covid-19, momento em que a indústria da construção civil foi uma das áreas mais impactadas pelo desemprego, notando-se 
quedas nas vendas de produtos e serviços, embargos de obras, redução das jornadas de trabalho, alta do dólar e bloqueios nas exportações, é a área mais bem avaliada da empresa e se encontra com o maior coeficiente de desempenho.

Esta área funcional se manteve estável, podendo, assim, ser considerada um ponto forte da organização. Pode-se observar na Tabela 02 os níveis e graus de avaliação referentes à área funcional do setor supracitado.

Tabela 02 - Avaliação de Desempenho das Finanças

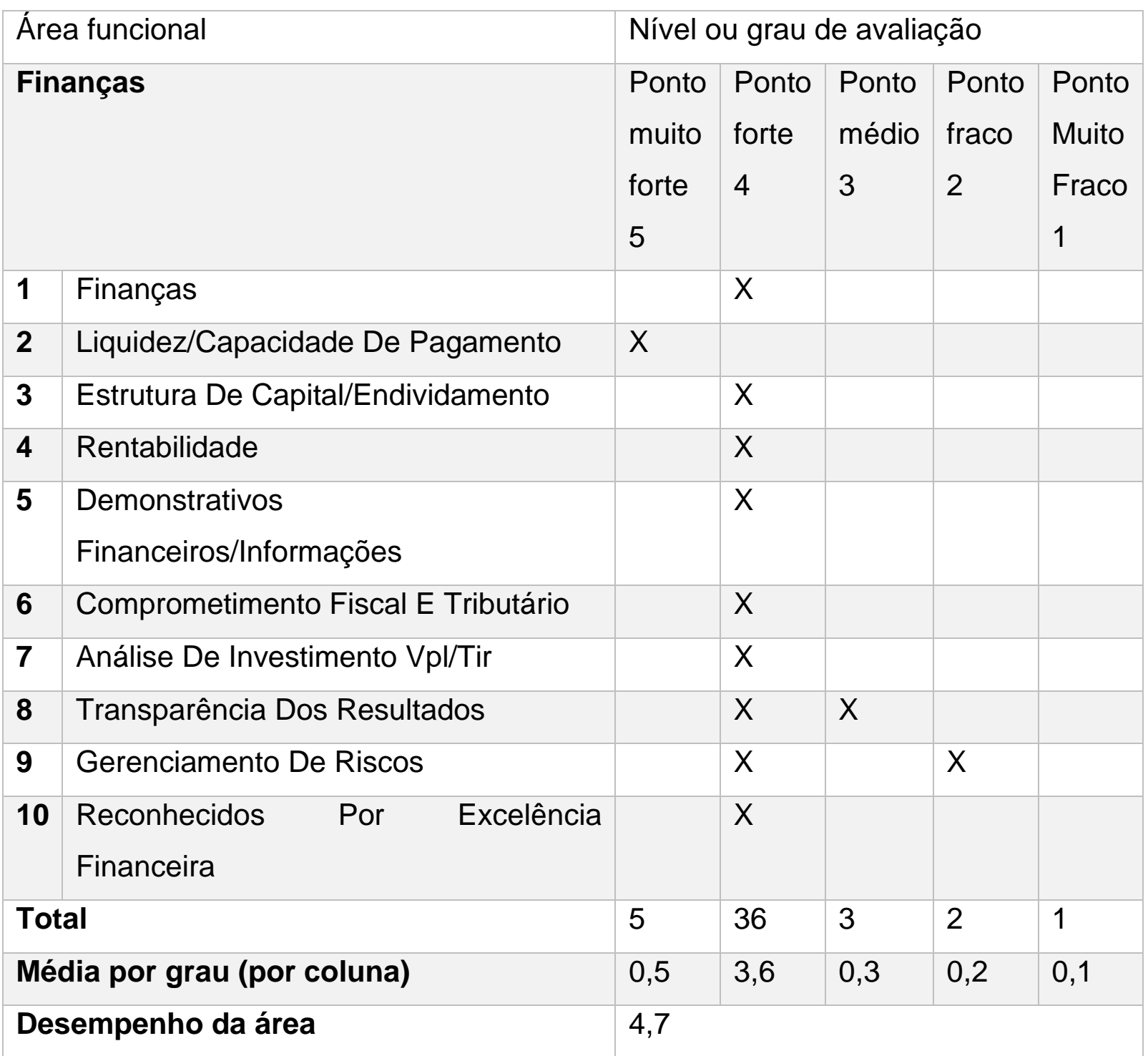

Fonte: Elaborado pelos autores com dados da Linear Engenharia, 2021

RC: 102091

Disponível em: https://www.nucleodoconhecimento.com.br/administracao/setor-deengenharia 
Por outro lado, o menor coeficiente de desempenho é o Marketing. É perceptível que organização não segue parâmetros e novas técnicas e tampouco explora aspectos inovativos para esta área funcional, conforme pode ser visto na tabela 03.

Tabela 03 - Avaliação de Desempenho do Marketing

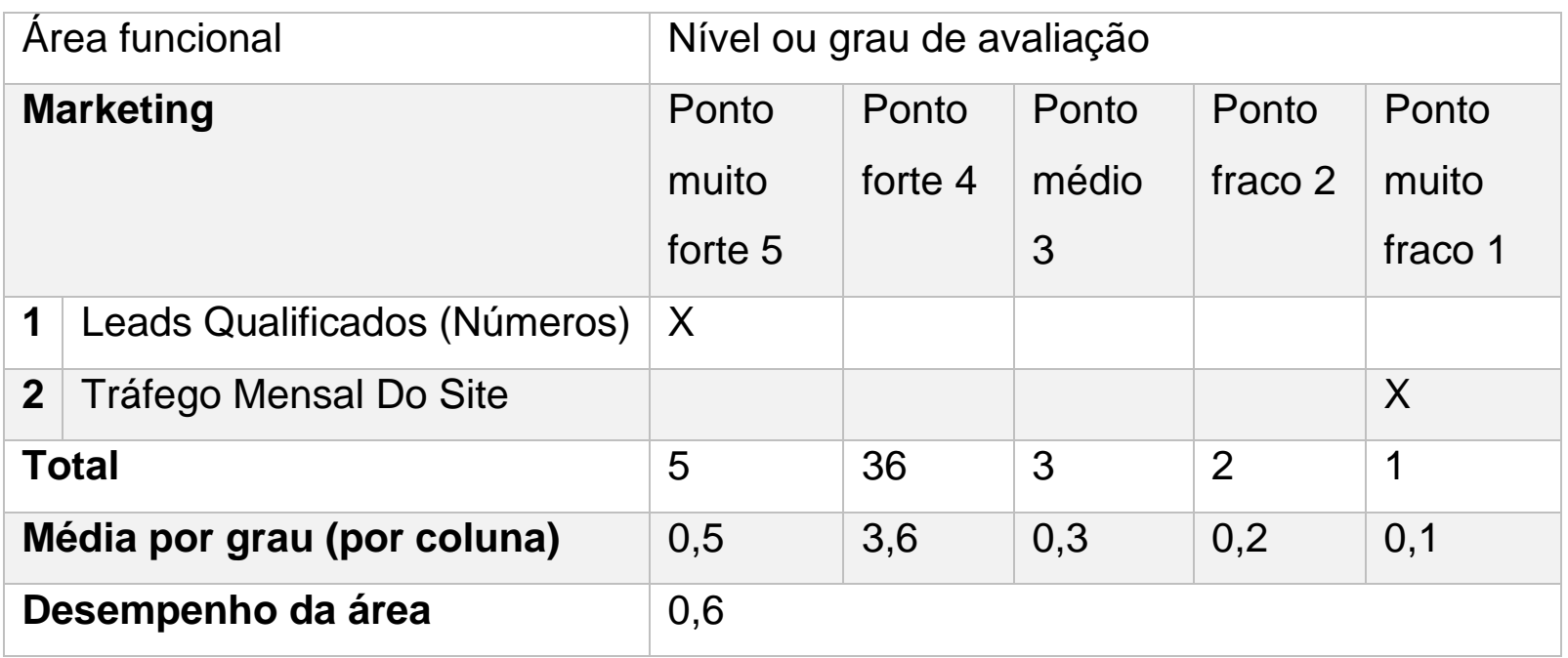

Fonte: Elaborado pelos autores com dados da Linear Engenharia, 2021

Muitas empresas ocultaram-se no mercado involuntariamente, justamente pelo lapso na busca e na aplicação das ferramentas fundamentais deste setor, bem como em virtude da utilização das características primordiais, sendo elas a criação e a inovação.

Assim sendo, o problema do artigo constitui-se em: como inovar-se no marketing e diferenciar-se no setor da construção civil, principalmente no ramo da engenharia civil, por meio de um planejamento mais estratégico, técnico e otimizado, promovendo o aumento das vendas de produtos e serviços, da lucratividade e da visibilidade positiva frente às outras empresas e em razão da necessidade da efetivação de clientes fixos, atrelando-se ao cenário pandêmico do Covid-19. Visando responder: como pode ser reinventado o negócio para suprimir as dificuldades e diferenciar-se no mercado da Construção Civil, diante a outras empresas do mesmo ramo, considerando os impactos da pandemia do Covid-19? 


\subsection{PLANEJAMENTO DE AÇÕES}

O Planejamento de Ações é a criação das trajetórias a serem alcançadas para que a empresa atinja determinados objetivos, ditando o modo como a organização deve atuar frente ao planejamento estratégico imposto por meio das ações interventivas.

Sendo assim, o planejamento de ações aqui desenvolvido leva em consideração o cenário pandêmico do Covid-19, que se encontra sem previsão de cessar, inserindo pontos fundamentais adotados durante esta ocorrência mundial, como, por exemplo, o distanciamento social, um dos principais fatores que alavancaram a utilização do marketing digital.

Quadro 01 - Ações interventivas

\begin{tabular}{|c|c|c|c|c|}
\hline Item & Ação interventiva & Procedente & onologia & Custo \\
\hline 1. & $\begin{array}{l}\text { Investimentos nos } \\
\text { métodos Inbound e } \\
\text { Outbound Marketing. }\end{array}$ & $\begin{array}{lr}\text { Falta } & \text { de } \\
\text { investimentos } & \text { em } \\
\text { anúncios } & \text { e } \\
\text { ferramentas. } & \end{array}$ & $\begin{array}{l}\text { Uma } \\
\text { semana. }\end{array}$ & $\begin{array}{l}\mathrm{R} \$ \\
1.600,00\end{array}$ \\
\hline 2. & $\begin{array}{l}\text { Implementação do } \\
\text { SEO. }\end{array}$ & $\begin{array}{l}\text { Falta de melhoria } \\
\text { técnica do site. }\end{array}$ & $\begin{array}{l}\text { Uma } \\
\text { semana. }\end{array}$ & $R \$ 3.000$ \\
\hline 3. & $\begin{array}{l}\text { Otimização das } \\
\text { Redes Sociais. }\end{array}$ & $\begin{array}{lr}\text { Falta } & \text { de } \\
\text { padronização } & \text { e } \\
\text { conteúdos } & \\
\text { relevantes. } & \end{array}$ & $\begin{array}{l}\text { Quatro } \\
\text { dias. }\end{array}$ & $\begin{array}{l}R \$ \\
1.500,00\end{array}$ \\
\hline 4. & $\begin{array}{l}\text { Eventos/Jornadas } \\
\text { digitais no segmento } \\
\text { da Construção Civil. }\end{array}$ & $\begin{array}{l}\text { Falta de oferecimento } \\
\text { de alguns produtos } \\
\text { para amostras. }\end{array}$ & $\begin{array}{l}\text { Duas } \\
\text { semanas. }\end{array}$ & $\mathrm{R} \$ 680,00$ \\
\hline 5. & $\begin{array}{l}\text { Treinamento da } \\
\text { equipe responsável e } \\
\text { mão de obra } \\
\text { especializada. }\end{array}$ & $\begin{array}{l}\text { Falta de treinamento } \\
\text { da } \\
\text { responsável e } \\
\text { de }\end{array}$ & $\begin{array}{l}\text { Duas } \\
\text { semanas. }\end{array}$ & $\begin{array}{l}\mathrm{R} \$ \\
1.927,00\end{array}$ \\
\hline
\end{tabular}


especializada.

Total

Fonte: Elaborado pelos autores, 2021.

Conforme o Quadro 01, foram pontuadas ações interventivas já presentes no âmbito de atuação do Marketing, escolhidas atentando-se às necessidades específicas, buscando otimizar e flexibilizar a produção do aspecto organizacional de marketing e desenvolvendo, em conjunto, uma estimativa orçamentária para cada operação.

\subsection{FERRAMENTA DA QUALIDADE PARA IMPLEMENTAÇÃO 5W2H}

Para proporcionar maior efetividade na aplicação das ações e levar a concretização de cada etapa, foi inserida a ferramenta da qualidade 5W2H. Essa ferramenta é utilizada com intuito de identificar as ações e os aspectos responsáveis aplicados à execução do planejamento por meio de sete perguntas. Morais (2017) explica que a definição de metas é saudável para o crescimento da empresa, porém, nem sempre há possibilidade de concluir os objetivos no prazo estabelecido. Para que isso ocorra de forma concreta e efetiva, uma boa solução é desenvolver um planejamento de ação baseado nesta ferramenta.

\subsubsection{INVESTIMENTOS NOS MÉTODOS INBOUND E OUTBOUND MARKETING}

O primeiro passo para a execução do planejamento de ações para a melhoria do desempenho do Marketing da Linear Engenharia Eireli iniciou-se por meio da aplicação dos métodos de marketing Inbound e Outbound.

O método Inbound é um tipo de marketing de comunicação direta, em que a empresa procura pelo cliente, desempenhando um relacionamento que pode ser duradouro. O método Outbound, também denominado Marketing Tradicional e de

RC: 102091

Disponível em: https://www.nucleodoconhecimento.com.br/administracao/setor-deengenharia 
percepção ativa, tem como o objetivo principal abordar clientes em potencial que condizem com o perfil do cliente ideal, com vistas a despertar o interesse do cliente pela empresa.

Quadro 02 - 5W2H - Investimentos nos métodos Inbound e Outbound Marketing

Métodos Inbound e Outbound Marketing

O que? Aplicação dos Métodos Inbound e Outbound.

Por quê? Para aumentar o número de vendas de produtos e serviços e desempenhar um relacionamento duradouro com os clientes.

Onde? Nas redes sociais, sites e pessoas físicas.

Quando? Primeira semana de janeiro de 2022.

Quem? Departamento de Marketing.

Como? Mediante o investimento financeiro para gerir anúncios digitais e contratação de serviços gráficos para a elaboração de placas e panfletos, e pessoas para abordagens físicas de clientes específicos.

\section{Quanto? $R \$ 1.600,00$}

Fonte: Elaborado pelos autores, 2021.

Conforme Quadro 02, apesar de uma estratégia ser diferente da outra, a utilização de uma ferramenta não anula o potencial da outra. Com base nisso, espera-se que, na primeira semana de janeiro de 2022, ambas proporcionem retorno sobre o investimento de forma única. Devem ser aplicadas após análises circunstanciais para demandas específicas, tanto digitalmente quanto fisicamente, proporcionando o aumento da contratação de serviços e vendas de produtos e objetivando a fidelização dos clientes. 


\subsubsection{IMPLEMENTAÇÃO DO SEO (SEARCH ENGINE OPTIMIZATION)}

A Otimização do Mecanismo de Busca é uma técnica estratégica utilizada no Marketing Digital. O objetivo principal dessa técnica é melhorar a classificação do site e facilitar a busca da empresa de acordo com o segmento no qual ela atua.

A implementação da técnica SEO (Search Engine Optimization) é estruturada em diversos aspectos, os principais são: a verificação das adversidades de rastreamento, a utilização da ferramenta de inspeção de URL por meio do Screaming Frog, a utilização da ferramenta Google API para indexação, desenvolvimento e implantação de links em páginas importantes, dentre outros.

Quadro 03 - 5W2H - Implementação do SEO (Search Engine Optimization)

Implementação do SEO

O que? Implantação da técnica Search Engine Optimization (SEO)

Por quê? Para otimizar o site, produzir conteúdo de qualidade e conquistar backlinks.

Onde? No site da empresa Linear Engenharia Eireli.

Quando? Primeira semana de fevereiro de 2022.

Quem? Departamento de Marketing e Tecnologia da Informação.

Como? Mediante ao treinamento da equipe responsável atrelado ao oferecimento de infraestrutura de rede sancionada pelo setor de TI.

Quanto? $R \$ 3.000,00$

Fonte: Elaborado pelos autores, 2021.

De acordo com o Quadro 03, foi desenvolvido o planejamento de ação para a primeira semana de fevereiro por meio da implementação da ferramenta SEO. Pretende-se que o departamento de marketing se encarregue do treinamento da equipe responsável, em conjunto ao setor de Tecnologia da Informação e Comunicação, oferecendo infraestrutura de rede para a implementação da 
ferramenta supracitada. Espera-se o aumento de vendas dos produtos e serviços, maior visibilidade da empresa frente às outras organizações do segmento, apreciação pela qualidade do conteúdo gerenciado e, consequentemente, potenciais clientes fixos ideais.

\subsubsection{OTIMIZAÇÃO DAS REDES SOCIAIS}

Para evitar a proliferação e infecção do Coronavírus durante a pandemia, foram adotados vários meios de contenção, o principal deu-se pelo isolamento social. As redes sociais já eram bastante utilizadas antes do cenário pandêmico do Covid-19, mas após a implantação das medidas de distanciamento esses números aumentaram. $\mathrm{O}$ uso da internet se potencializou com o objetivo de manter algumas rotinas, como, por exemplo, a interação com amigos e familiares distantes, o home office e as aulas online.

É evidente que a indústria e o comércio tiveram que se adaptar à nova realidade e que o destaque nesse mundo digital das redes sociais se dá pela relevância do conteúdo, organização e disciplina. Portanto, ao se inserir no mundo tecnológico, a empresa acaba por se tornar referência em frente às outras organizações.

A partir disto, pode ser utilizado o conceito SMO (Social Media Optimization), que diz respeito à ampliação e à estratégia da marca da empresa, proporcionando a redução de custo com o marketing, aumentando a relação da organização e cliente e abordando, também, a implementação do SEO.

Quadro 04 - 5w2h - Otimização das Redes Sociais

\section{Otimização das Redes Sociais}

O que? Padronização e execução de conteúdos relevantes.

Por quê? Para se destacar das demais empresas, facilitando o encontro da Linear Engenharia por clientes em potencial.

Onde? Nas Redes Sociais da Linear Engenharia Eireli. 
Quando? Primeira Semana de Janeiro de 2022.

Quem? Departamento de Marketing.

Como? Mediante a elaboração de programação de postagens e conteúdos relevantes através de ferramentas gerenciadoras de redes sociais.

Quanto? $\mathrm{R} \$ 1.500,00$

Fonte: Elaborado pelos autores, 2021.

Conforme o Quadro 04, foi desenvolvido, para a primeira semana de janeiro de 2022, o planejamento de ação para a otimização das redes sociais. Espera-se que a implantação desta ação proporcione a automatização de posts inteligentes, interativos e relevantes, buscando não apenas novos e fiéis clientes, mas também busca-se abranger, de forma geral, uma maior flexibilidade, agilidade e otimização do trabalho.

\subsubsection{EVENTOS/JORNADAS DIGITAIS NO SEGMENTO DA CONSTRUÇÃO CIVIL}

Ao investir no oferecimento de eventos tipo workshops, jornadas e webinar, a empresa obtém um aumento considerável no relacionamento efetivo com os clientes, o que também ajuda a atrair novos clientes em potencial.

Não apenas devido à pandemia, antes os eventos feitos de modo online já eram muito mais eficientes por oferecerem a possibilidade de alcançar um número muito maior de espectadores, o que não ocorria em eventos que exigiam a presença física do espectador, pois se restringiam conforme a localização. Sendo assim, eventos e jornadas digitais são pontos cruciais para o aumento da visibilidade empresarial frente às outras empresas.

Quadro 05 - 5W2H - Eventos/Jornadas digitais no segmento da Construção Civil

Eventos/Jornadas digitais no segmento da Construção Civil 
O que? Oferecimento de Eventos/Jornadas Digitais na área de atuação da Linear Engenharia Eireli.

Por quê? Para aumentar a visibilidade positiva da empresa frente às outras e melhorar o relacionamento com os clientes.

Onde? Site da empresa ou o site gratuito organizador de eventos: www.even3.com.br

Quando? Terceira e quarta semana de fevereiro de 2022.

Quem? Departamento de Marketing.

Como? Através do Site da empresa ou o site gratuito organizador de eventos, sendo anunciado nas redes sociais e e-mail cadastrados.

Quanto? $R \$ 680,00$

Fonte: Elaborado pelos autores, 2021.

Conforme o Quadro 05, foi desenvolvido um plano de ação focado na realização de eventos digitais, a fim de aumentar o fluxo de participação de pessoas específicas, promovendo o aumento da visibilidade da empresa frente às outras do ramo. $A$ implementação das ações será efetuada na terceira e quarta semana de fevereiro de 2022. Além da efetividade do relacionamento com os clientes, devido a transmissão de um evento pertinente e interessante que abrange o segmento de atuação, o custo reduzido e a lucratividade tornam-se um dos grandes fatores para fundamentar a execução desses eventos, sendo que podem ser organizados por meio de site gratuitos como o Even3 ou a partir do próprio site institucional.

\subsubsection{TREINAMENTO DA EQUIPE RESPONSÁVEL E MÃO DE OBRA TERCEIRIZADA}

O crescimento e o sucesso de uma empresa estão atrelados ao desenvolvimento dos profissionais atuantes na organização, portanto, os treinamentos para desenvolver competências da equipe, para a efetivação de determinadas tarefas, aumentam a produtividade e a eficiência na execução das atividades designadas, logo, geram melhor desempenho nos aspectos organizacionais. 
Quadro 06 - 5W2H - Treinamento da Equipe responsável e mão de obra especializada

Treinamento da Equipe responsável e mão de obra especializada

O que? Treinamento da equipe responsável e contratação de mão de obra especializada.

Por quê? Para aumentar a produtividade e aplicação correta das técnicas de marketing.

Onde? Nas instalações da Linear Engenharia Eireli.

Quando? Primeira semana de janeiro de 2022.

Quem? Departamento de Recursos Humanos.

Como? Através de recrutamento e seleção.

Quanto? $\mathrm{R} \$ 1.927,00$

Fonte: Elaborado pelos autores, 2021.

Conforme o Quadro 06, foi apresentado o plano de ações para aumentar a produtividade e aplicar, de forma efetiva, as ações citadas anteriormente. A implementação deste plano ocorrerá na primeira semana de janeiro de 2022. O marketing exige mão de obra especializada e profissionais com competências e habilidades para a utilização e criação de ferramentas. Espera-se que a necessidade de mão de obra especializada seja findada e que o treinamento das equipes já existentes proporcione habilidades para criar métodos e estratégias de forma ágil, automatizada e notória, à nível interno e externo.

\subsection{FLUXOGRAMA DA PROPOSTA}

Após a análise dos dados coletados por meio do Diagnóstico Organizacional da empresa Linear Engenharia Eireli e do o desenvolvimento estratégico para a aplicação das ações interventivas, utilizando a ferramenta 5W2H para identificar os pontos essenciais e auxiliar na criação de metas, foi desenvolvido um fluxograma demonstrando o trajeto a ser traçado para que o objetivo principal seja alcançado, 
sendo este aplicado por meio de um fluxo coerente e interligado, no qual cada ação ampara-se em uma única finalidade.

Figura 01 - Fluxograma da proposta.

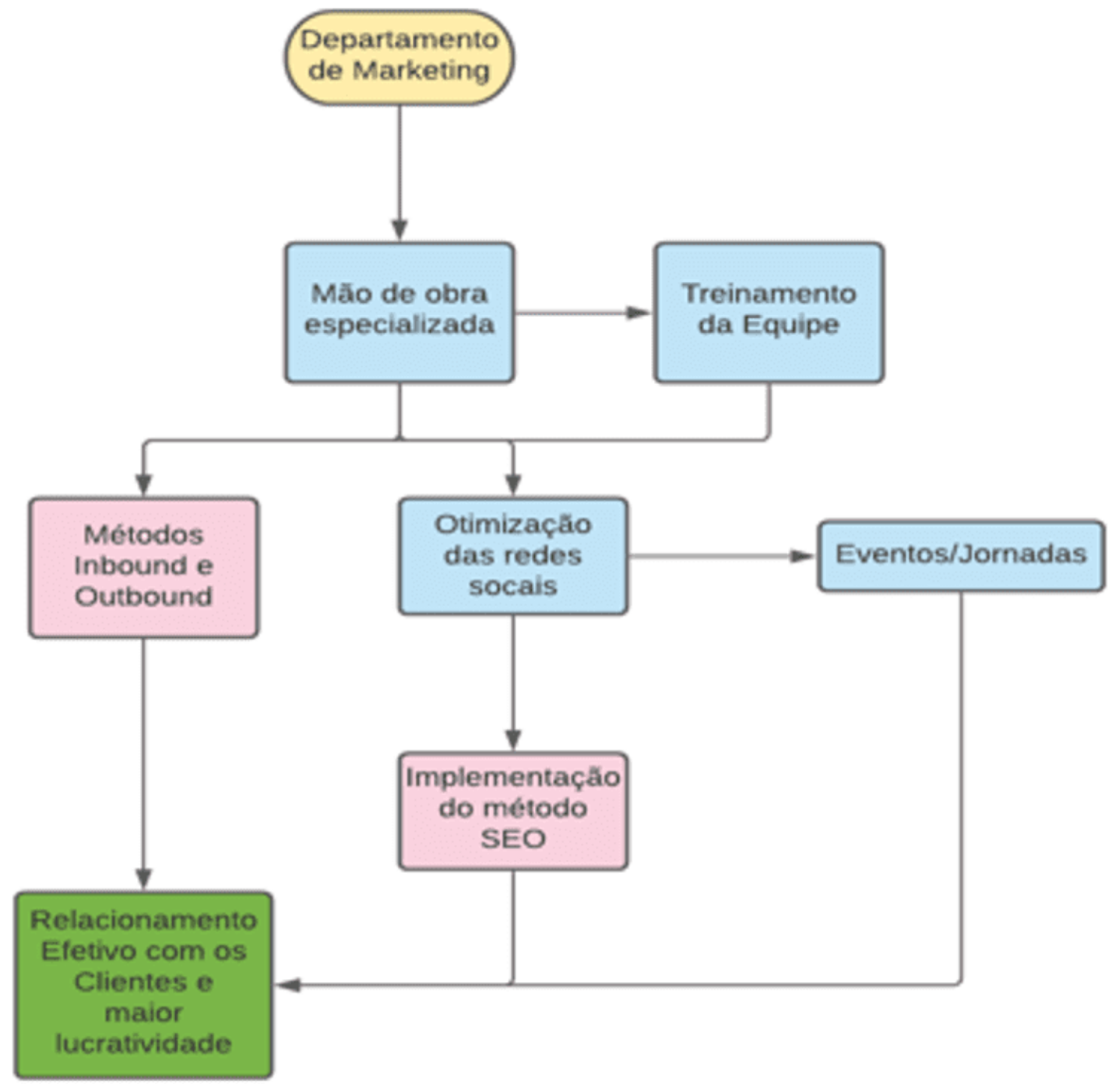

Fonte: Elaborado pelos autores, 2021

A figura 01 mostra o fluxograma em questão, em que se dá início a contratação de mão de obra especializada e treinamento das equipes. Em seguida, aplica-se às ações, resultando no crescimento organizacional, elevando o relacionamento efetivo com os clientes, e, consequentemente, aumentando a lucratividade, reinventando a 
empresa diante o cenário atual da pandemia, tornando-a mais visível no setor da Construção Civil, especialmente no ramo da Engenharia Civil.

\section{CONSIDERAÇÕES FINAIS}

A partir das premissas, contextualização e o estudo de caso realizado junto à empresa de pequeno porte Linear Engenharia Eireli, atuante do ramo da Engenharia Civil, concluiu-se, por meio de um Diagnóstico Organizacional, que a área funcional de melhor desempenho desta organização, surpreendentemente, é a área de finanças. Ponto extremamente positivo, já que a indústria da Construção Civil está em um momento crítico e tentando reinventar-se e adaptar-se em meio ao cenário pandêmico.

A partir dos objetivos gerais e específicos, analisou-se as proporções do impacto da pandemia sob os aspectos organizacionais, tendo-se identificado o Marketing como a área de desempenho mais caótica. E para atingir as circunstâncias, visando otimizar os recursos, motivar e integrar as equipes, foi definido o posicionamento da organização frente a este cenário por meio do desenvolvimento de um planejamento estratégico com ações específicas para a área de marketing.

A estratégias elaboradas em prol da melhoria no déficit da área funcional do marketing foram alcançadas de forma positiva, atendendo às necessidades da problemática em questão, no qual foram impostas sugestões de ações interventivas considerando os fatores identificados por meio da avaliação de desempenho na área supracitada, suprimindo-os com técnicas efetivas existentes do marketing. $O$ objetivo foi alcançado, principalmente, pela sugestão de treinamento e contratação de mão de obra especializada, o que faz com que as demais ações obtenham um melhor aproveitamento após serem aplicadas.

Desse modo, este artigo conseguiu responder à indagação referente a como se pode suprimir as dificuldades e reinventar o negócio frente a outras organizações, considerando o efeito do Covid-19 sob a atuação das empresas do ramo da 
engenharia civil. A resposta foi auferida a partir da aplicabilidade da metodologia do plano de ações e auxiliada pela utilização da ferramenta $5 \mathrm{~W} 2 \mathrm{H}$, que proporcionou versatilidade e utilidade na composição da planificação das ações, influenciando no crescimento da organização como todo.

Isto posto, a recomendação é a realização de avaliações periódicas das áreas funcionais para que se identifique o grau de desempenho de cada aspecto, devido ao fato do segmento da Construção Civil se encontrar em constantes mudanças e às empresas de Engenharia Civil estarem em processos de adaptabilidade.

Também se salienta que este artigo pode ser utilizado como base para futuros estudos, porém, não como solução específica para todas as organizações, sendo elas públicas ou privadas, posto que cada caso é particular e demanda um diagnóstico quanto aos aspectos organizacionais distintivos.

\section{REFERÊNCIAS}

AMARC. Como está o cenário da construção civil na pandemia?. ARMARC. 2021. Disponível em: https://armac.com.br/blog/engenharia/construcao-civil-napandemia. Acesso em: 07/08/2021.

AGÊNCIA 404. Marketing na crise: não é hora de parar! É hora de se reinventar. Agência 404, 2020. Disponível em: https://a04.com.br/marketing-na-crise-nao-ehora-de-parar-e-hora-de-se-reinventar/. Acesso em: 26/10/2021.

ARANHA, Daniela Monteiro Bispo. Procura por marketing digital dispara na pandemia. SEGS, 2021. Disponível em: https://www.segs.com.br/seguros/309843procura-por-marketing-digital-dispara-na-pandemia. Acesso em: 27/10/2021.

AZEVEDO, Rafaella. 6 tendências de RH para 2021. Edu Job, 2021. Disponível em: https://edujob.com.br/6-tendencias-de-rh-para-2021/. Acesso em: 27/10/2021. 
CBIC, Agência. Resultados do PIB Brasil e da construção no $1^{\circ}$ trimestre surpreendem. CBIC, 2021. Disponível em: https://cbic.org.br/resultados-do-pibbrasil-e-da-construcao-no-10-trimestre-surpreendem/. Acesso em: 03/08/2021.

CERVO, A. L.; BERVIAN, P. A.; DA SILVA, R. Metodologia científica. 6 ed. São Paulo: Pearson Prentice Hall, 2007.

CHIAVENATO, Idalberto. Teoria Geral da Administração: abordagens prescritivas e normativas. Vol. I. 7.ed. Barueri: Manole, 2014.

COELHO, Yeska. Escritórios Pós-Pandemia: Especialista do elenco casa cor dão dicas. Casa $\quad$ Cor, 2021 Disponível https://casacor.abril.com.br/arquitetura/escritorios-pos-pandemia/. Acesso em: 03/08/2021.

COLTRE, Sandra Maria. Fundamentos de administração: um olhar transversal. Curitiba: Intersaberes, 2014.

CORRÊA, H. L. CORRÊA, C. A. Administração de produção e operações: manufatura e serviços: uma abordagem estratégica. 2 ed. São Paulo: Atlas, 2011. 690 páginas.

DAU, Gabriel. Transformação digital: pandemia impulsiona revolução e inovação nas empresas. Jornal Contábil, 2020. Disponível em: https://www.jornalcontabil.com.br/pandemia-impulsiona-transformacao-nasempresas/. Acesso em: 27/10/2021.

DIAS, Ana; SILVA, Fabiano; VIEIRA, Nádia; SILVA, Sandro. A Construção Civil e os Trabalhadores: panorama dos anos recentes. № 95. São Paulo: Diese, 2020.

FACHIN, Odília. Fundamentos de metodologia. 5. ed. São Paulo: Saraiva, 2012. 
FREITAS, Cristiano. MEI \#11: Qual o conceito de operação de uma empresa?. Syhus Contabilidade, 2016. Disponível em: https://syhus.com.br/2016/05/31/mei-11qual-o-conceito-de-operacao-de-uma-empresa/. Acesso em: 04/08/2021.

GOVERNO DO BRASIL. OMS declara emergência de saúde pública internacional para novo coronavírus. Governo do Brasil, 2020. Disponível em: https://www.gov.br/pt-br/noticias/saude-e-vigilancia-sanitaria/2020/01/oms-declaraemergencia-de-saude-publica-internacional-para-novo-coronavirus. Acesso em: 20/08/2021.

HANDA, Márcio. Maior geração de empregos do país na construção civil. Revista Grandes Construções, 2021. Disponível em: https://www.grandesconstrucoes.com.br/Noticias/Exi-bir/maior-geracao-deempregos-do-pais-esta-na-construcao-civil/. Acesso em: 05/08/2021.

KOTLER, Philip. Marketing 4.0: do tradicional ao digital. Rio de Janeiro: Sextante, 2017.

KOTLER, P., \& KELLER, K. L. (2012). Administração de marketing. 14. ed. São Paulo: Pearson Prentice Hall.

LAKATOS, E. M.; MARCONI, M. A. Metodologia científica. 6. ed. São Paulo: Atlas, 2011.

LUNARDELLI, Paula. Indústria da construção: como está o cenário e quais os impactos da pandemia. Sienge Plataforma. Disponível em: www.sienge.com.br/blog/industria-da-construcao-impactos-da-pandemia/. Acesso em: 03/08/2021.

MARCONI, Maria de Andrade. Lakatos, Eva Maria. Metodologia Científica. 2. ed. São Paulo: Altas, 1990. 
MARCONI, M. A.; LAKATOS, E. M. Fundamentos da metodologia científica. 6. ed. São Paulo: Atlas, 2009.

MARTINS, José. Tendências da construção civil em 2019. Sienge, 2018. Disponível em: https://www.sienge.com.br/blog/tendencias-da-construcao-civil-2/. Acesso em: 04/08/2021.

MESQUITA, Aline. Home Office permanente: desafio para o $\mathrm{RH}$ e colaboradores. Oitchau, 2020. Disponível em: https://www.oitchau.com.br/blog/home-officepermanente-desafio-para-o-rh-e-colaboradores/. Acesso em: 04/08/2021.

MORAIS, Edilson. Como elaborar um plano de ação com ferramenta 5W2H. Conta Azul, 2017. Disponível em: https://blog.contaazul.com/como-elaborar-umplano-de-acao-com-a-ferramenta-5w2h. Acesso: em 03/08/2021.

MOTT, David; BLASCO, Lucia. Home Office e Covid-19: Cinco modelos de "escritórios do futuro" antecipado pela pandemia. BBC News, 2020. Disponível em: https://noomis.febraban.org.br/te-mas/inovacao/home-office-e-covid-19-cincomodelos-de-escritorio-do-futuro-antecipados-pela-pandemia. Acesso em: 03/08/2021.

NERY, Carmem. PIB cresce 1,1\% e fecha 2019 em R\$ 73 trilhões. Agência IBGE notícias. 2020. Disponível em: https://agenciadenoticias.ibge.gov.br/agencianoticias/2012-agencia-de-noticias/noticias/27007-pib-cresce-1-1-e-fecha-2019-em-r7-3-trilhoes. Acesso em: 10/08/2021.

OLIVEIRA, Amir. Construção civil como termômetro da economia. Tribunal de Minas. 2019. Disponível em: https://tribunademinas.com.br/colunas/conjunturamercado/07-05-2019/construcao-civil-como-termometro-da-economia.html. Acesso em: 11/08/2021. 
PEÇANHA, Vitor. O que é Marketing Digital? Tudo sobre o conceito, como fazer e começar sua estratégia de Marketing Online em 2021. Rock Content. Disponível em: https://rockcontent.com/br/blog/marketing-digital. Acesso em: 03/08/2021.

PEROVANO, D.G. Manual de metodologia científica para a segurança pública e defesa social. Curitiba: Juruá, 2014.

SANTOS, João Maria Fermino dos. Os desafios do administrador em tempos de pandemia. CRA-PR, 2020. Disponível em: https://cra-pr.org.br/os-desafios-doadministrador-em-tempos-de-pandemia/. Acesso em: 27/10/2021.

SBPT, Sociedade Brasileira de Pneumologia e Tisiologia. Orientações da OMS para prevenção do Covid-19: folha informativa sobre COVID-19. SBPT, 2020. Disponível em: https://sbpt.org.br/portal/covid-19-oms/. Acesso: em 14/08/2021.

SOBRAL, Filipe; PECl, Alketa. Administração: teoria e prática no contexto brasileiro. 2.ed. São Paulo: Pearson, 2013.

THIOLLENT, Michel. Metodologia da Pesquisa-Ação. São Paulo: Cortez, 2009.

TPC, Sistemas. A construção civil na pandemia: como está essa indústria? TPC Sistemas, 2021. Disponível em: https://tcpsistemas.com.br/a-construcao-civil-napandemia/. Acesso em: 06/08/2021.

VALENTE, Jonas. OMS declara estado de emergência global em razão do coronavírus. Agência Brasil EBC, 2020. Disponível em: https://agenciabrasil.ebc.com.br/saude/noticia/2020-01/oms-declara-estado-deemergencia-global-em-razao-do-coronavirus. Acesso em: 28/10/2021.

YOON, S. J., LIN, H. K., CHEN, G., YI, S., CHOI, J.; RUI, Z. (2013). Effect of occupational health and safety management system on work - related accident rate and differences of occupational health and safety management 
system awareness between managers in South Korea's construction industry. Safety and health at work, 4 (4), $201-209$.

Enviado: Outubro, 2021.

Aprovado: Novembro, 2021. 